\title{
MENENTUKAN PUNCAK EROSI POTENSIAL YANG TERJADI DI DAERAH ALIRAN SUNGAI (DAS) LOLI TASIBURI DENGAN MENGGUNAKAN METODE USLE
}

\author{
Minarni' ${ }^{1}$, A. I. Jaya², Fadjryani3 \\ 1Program Studi Matematika Jurusan Matematika FMIPA Universitas Tadulako \\ Jalan Soekarno-Hatta Km. 09 Tondo, Palu 94118, Indonesia. \\ ${ }^{1}$ Nannykiango@yahoo.co.id, 2ratianingsih@yahoo.com
}

\begin{abstract}
Potensial erosion is the erosion of the soil that produces under the open sky. The main cause of erosion is the factor of erosividad, erodibilitas factor, and slope factor. This study uses the Universal Soil loss equation (USLE) to predict the amount of erosion that occurred. USLE method can be described as a design that is used to predict soil loss generated by the erosion in sediment slope segment, while also it's designed to estimate the average amount of erosion for a long time. From the results is obtained that the erosion peak occurred in 2000 with the potential erosion of $1114,329.790$ tons / year.
\end{abstract}

Keyword : Erosion Potensial Method, Erosion Potential of Large, Peak Potential Erosion, Universal Soil Loss Equation (USLE)

\section{ABSTRAK}

Erosi Potensial merupakan erosi yang terjadi pada tanah yang terbuka. Penyebab utama penyebab terjadinya erosi adalah faktor erosivitas, faktor erodibilitas dan faktor kelerengan. Penelitian ini menggunakan metode Universal Soil Loss Equation (USLE) untuk menghitung besar erosi yang terjadi. Metode USLE dapat dijelaskan sebagai desain yang digunakan untuk menghitung kehilangan tanah yang dihasilkan oleh erosi diendapan pada segmen lereng, selain itu juga didesain untuk menghitung rata-rata jumlah erosi dalam waktu yang panjang. Dari hasil perhitungan didapatkan bahwa puncak erosi terjadi pada tahun 2000 dengan besar erosi potensial yaitu 1114329,790 Ton/Tahun.

Kata Kunci : Besar Erosi Potensial, Erosi Potensial, Metode Universal Soil Loss Equation (USLE), Puncak Erosi Potensial 


\section{PENDAHULUAN}

\subsection{Latar Belakang}

Daerah aliran sungai (DAS) merupakan suatu kawasan (wilayah) penerima air hujan yang dibatasi oleh punggung bukit atau gunung, dimana semua curah hujan yang jatuh diatasnya akan mengalir disungai utama dan akhirnya bermula ke laut. Masalah DAS di Indonesia umumnya terjadi karena penggunaan tanah yang tidak tepat sehingga menyebabkan pruduktivitas tanah menurun. Tanah yang tidak produktif lama kelamaan pada periode tertentu mengakibatkan terjadinya erosi. Penelitian ini bertujuan untuk menentukan puncak erosi dan besar erosi yang terjadi pada saat puncak erosi terjadi.

\subsection{Rumusan Masalah}

Berdasarkan latar belakang yang telah diuraikan, maka dapat dirumuskan permasalahan yaitu bagaimana erosi yang terjadi dengan variasi curah hujan pada DAS Lolitasiburi.

\subsection{Tujuan Penelitian}

Penelitian ini bertujuan untuk mengetahui besar erosi yang terjadi di DAS Lolitasiburi, sehingga nantinya dapat diketahui kapan terjadinya puncak erosi di DAS Lolitasiburi selama kurun waktu penelitian.

\section{METODE PENELITIAN}

\subsection{Sungai}

Sungai adalah perpaduan antara alur sungai dengan aliran air didalamnya. Alur sungai adalah suatu alur yang panjang diatas permukaan bumi tempat mengalirnya air yang berasal dari air hujan (Sastrodarsono,1984).

\subsection{Daerah Aliran Sungai}

Secara umum DAS dapat didefinisikan sebagai suatu wilayah daratan yang secara topografi dibatasi oleh punggung-punggung gunung yang menampung dan menyimpan air hujan untuk kemudian menyalurkannya ke laut melalui sungai utama. Wilayah daratan tersebut disebut tangkapan air (catchment area) yang merupakan suatu ekosistem dengan unsur utama terdiri atas sumber daya alam (tanah, air, dan vegetasi) dan sumberdaya manusia sebagai pemanfaat sumber daya alam (Asdak,2002). 


\subsection{Erosi}

Secara umum dikatakan sebagai proses terlepasnya butiran tanah dari induknya disuatu tempat dan terangkutnya material tersebut oleh gerakan air atau angin kemudian diikuti pengendapan material yang terangkut di tempat lain (Suripin,2002).

\subsection{Prakiraan Besarnya Erosi}

Metode USLE (Universal Soil Loss Eguation) merupakan metode yang umum digunakan untuk menghitung laju erosi. Selain sederhana, metode ini juga sangat baik diterapkan didaerah - daerah yang faktor utama penyebab erosi adalah hujan dan aliran permukaan. Metode USLE didesain untuk digunakan menghitung kehilangan tanah yang dihasilkan oleh erosi diendapan pada segmen lereng bukan pada hulu DAS, selain itu juga didesain menghitung rata - rata jumlah erosi dalam waktu yang panjang.

Faktor -faktor yang berpengaruh terhadap erosi potensial di Daerah Aliran Sungai (DAS) Loli Tasiburi adalah faktor erosivitas hujan, faktor erodibitas tanah, dan faktor kelerengan. Maka rumus yang digunakan adalah

$E p=R \times K \times L S$

dengan

$E p=$ Erosi Potensial

$R=$ Faktor Erosivitas curah hujan

$K=$ Faktor Erodibilitas tanah

$L S=$ Faktor Kelerengan

Untuk menghitung erosivitas curah hujan

$R=\sum_{t=1}^{n} E I_{30}$

dengan

$R=$ Faktor Erosivitas Curah Hujan

$n$ = Jumlah Kejadian Hujan dalam Setahun

$E I_{30}=$ Interaksi Energi dengan Intensitas Hujan Maksimum 30 Menit

(Suripin,2002)

Menghitung erodibilitas tanah gunakan rumus

$K=\left[\frac{2,71 \times 10^{-4}(12-D M) M^{1,14}+3,25(s-2)+2,5(P-3)}{100}\right]$

dengan

$D M=$ Persentase Bahan Organik

$M=$ Persen Ukuran Partikel $=(\%$ Debu $+\%$ Pasir Sangat Halus $) \times(100 \%-\%$ Liat $)$

$s=$ Kode Struktur Tanah Dipergunakan dalam Klasifikasi Tanah 
$P \quad=$ Kode permentasi tanah

Sedangkan untuk mengetahui nilai kelerengan maka rumus yang digunakan

$L S=\frac{\sqrt{L_{0}}}{100}\left(1,38+0,965 S+0,138 S^{2}\right)$

dengan

$L S=$ Faktor Kelerengan

$L_{0} \quad=$ Panjang Lereng dalam Meter $(\mathrm{m})$

$S \quad=$ Kemiringan Lereng dalam Persen (\%)

\subsection{Jenis Data}

Jenis data yang digunakan dalam penelitian ini adalah data kualitatif. Data ini merupakan data yang sudah tersedia berupa data curah hujan, data jenis tanah, dan data kemiringan lereng. Perhitungan besarnya nilai faktor erosifitas hujan $(R)$ disajikan dalam tabel berikut :

Tabel 1: Perhitungan Faktor Erosivitas Hujan (R) pada Tahun 1999

\begin{tabular}{|l|l|l|l|l|l|l|l|}
\hline Bulan & $\mathbf{R b}$ & $\mathbf{N}$ & $\mathbf{R m}$ & $\boldsymbol{R b}^{\mathbf{1 , 2 1 1}}$ & $\boldsymbol{N}^{-\mathbf{0 , 4 7 4}}$ & $\mathbf{R m}^{\mathbf{0 , 5 2 6}}$ & \multicolumn{1}{|c|}{$\mathbf{I}_{\mathbf{3 0}}$} \\
\hline Jan & 5,500 & 11,000 & 0,800 & 7,881 & 0,321 & 0,889 & 13,76 \\
Feb & 5,100 & 7,000 & 1,600 & 7,192 & 0,398 & 1,280 & 22,405 \\
Mar & 15,700 & 14,000 & 3,900 & 28,069 & 0,286 & 2,046 & 100,58 \\
Apr & 7,500 & 10,000 & 2,800 & 11,474 & 0,336 & 1,719 & 40,512 \\
Mei & 6,510 & 13,000 & 2,750 & 9,666 & 0,296 & 1,703 & 29,854 \\
Jun & 9,340 & 12,000 & 4,600 & 14,965 & 0,308 & 2,232 & 62,929 \\
Jul & 13,020 & 10,000 & 5,700 & 22,377 & 0,336 & 2,498 & 114,832 \\
Agst & 3,310 & 11,000 & 1,200 & 4,261 & 0,321 & 1,101 & 9,209 \\
Sept & 4,680 & 11,000 & 2,800 & 6,481 & 0,321 & 1,719 & 21,874 \\
Okt & 3,710 & 17,000 & 0,560 & 4,892 & 0,261 & 0,737 & 5,761 \\
Nov & 2,890 & 8,000 & 0,950 & 3,615 & 0,373 & 0,973 & 8,036 \\
Des & 2,750 & 6,000 & 1,100 & 3,404 & 0,428 & 1,051 & 9,368 \\
\multicolumn{7}{|l|}{ Jumlah } \\
\hline
\end{tabular}

Tabel 2: Perhitungan Faktor Erosivitas Hujan (R) pada Tahun 2000

\begin{tabular}{|l|l|l|l|l|l|l|l|}
\hline Bulan & $\boldsymbol{R} \boldsymbol{b}$ & $\boldsymbol{N}$ & $\boldsymbol{R} \boldsymbol{m}$ & $\boldsymbol{R b}^{\mathbf{1 , 2 1 1}}$ & $\boldsymbol{N}^{-\mathbf{0 , 4 7 4}}$ & $\boldsymbol{R m}^{\mathbf{0 , 5 2 6}}$ & $\boldsymbol{E I}_{\mathbf{3 0}}$ \\
\hline Jan & 7,330 & 12,000 & 2,500 & 11,159 & 0,308 & 1,619 & 34,049 \\
Feb & 4,180 & 10,000 & 1,420 & 5,653 & 0,336 & 1,203 & 13,965 \\
Mar & 4,220 & 13,000 & 1,100 & 5,718 & 0,296 & 1,051 & 10,907 \\
Apr & 2,380 & 9,000 & 1,040 & 2,858 & 0,353 & 1,021 & 6,300 \\
Mei & 1,350 & 5,000 & 0,950 & 1,438 & 0,466 & 0,973 & 3,995 \\
\hline
\end{tabular}




\begin{tabular}{|l|l|l|l|l|l|l|l|}
\hline Jun & 18,420 & 14,000 & 5,500 & 34,062 & 0,286 & 2,451 & 146,256 \\
Jul & 2,120 & 7,000 & 0,950 & 2,484 & 0,398 & 0,973 & 5,883 \\
Agst & 6,330 & 12,000 & 2,850 & 9,343 & 0,308 & 1,735 & 30,542 \\
Sept & 4,110 & 7,000 & 2,400 & 5,538 & 0,398 & 1,585 & 21,353 \\
Okt & 16,700 & 14,000 & 6,650 & 30,249 & 0,286 & 2,709 & 143,526 \\
Nov & 29,800 & 16,000 & 8,000 & 60,992 & 0,269 & 2,986 & 299,384 \\
Des & 10,000 & 11,000 & 2,480 & 16,255 & 0,321 & 1,612 & 51,469 \\
\hline \multicolumn{7}{|c|}{ Jumlah } \\
\hline
\end{tabular}

Tabel 3: $\quad$ Perhitungan Faktor Erosivitas Hujan (R) pada Tahun 2001

\begin{tabular}{|l|l|l|l|l|l|l|l|}
\hline Bulan & $\mathbf{R b}$ & $\mathbf{N}$ & $\mathbf{R m}$ & $\boldsymbol{R b}^{\mathbf{1 , 2 1 1}}$ & $\boldsymbol{N}^{\mathbf{0 , 4 7 4}}$ & $\mathbf{R m}^{\mathbf{0 , 5 2 6}}$ & \multicolumn{1}{|c|}{$\boldsymbol{I}_{\mathbf{3 0}}$} \\
\hline Jan & 2,840 & 14,000 & 0,860 & 3,540 & 0,286 & 0,924 & 5,727 \\
Feb & 10,580 & 15,000 & 3,100 & 17,404 & 0,277 & 1,813 & 53,496 \\
Mar & 9,210 & 13,000 & 2,500 & 14,714 & 0,296 & 1,619 & 43,222 \\
Apr & 9,330 & 12,000 & 2,800 & 14,946 & 0,308 & 1,719 & 48,404 \\
Mei & 11,650 & 8,000 & 2,850 & 19,558 & 0,373 & 1,735 & 77,479 \\
Jun & 2,780 & 9,000 & 0,830 & 3,449 & 0,353 & 0,907 & 6,754 \\
Jul & 9,030 & 6,000 & 5,170 & 14,366 & 0,428 & 2,373 & 89,222 \\
Agst & 2,740 & 4,000 & 0,900 & 3,389 & 0,518 & 0,946 & 10,171 \\
Sept & 12,930 & 15,000 & 2,650 & 22,189 & 0,277 & 1,670 & 62,804 \\
Okt & 6,470 & 8,000 & 3,800 & 9,594 & 0,373 & 2,018 & 44,217 \\
Nov & 7,260 & 15,000 & 3,650 & 11,030 & 0,277 & 1,976 & 36,947 \\
Des & 8,020 & 17,000 & 1,800 & 12,444 & 0,261 & 1,362 & 27,082 \\
\hline \multicolumn{7}{|l|}{ Jumlah } \\
\hline
\end{tabular}

Tabel 4: $\quad$ Perhitungan Faktor Erosivitas Hujan (R) pada Tahun 2002

\begin{tabular}{|l|l|l|l|l|l|l|l|}
\hline Bulan & Rb & $\mathbf{N}$ & $\mathbf{R m}$ & $\boldsymbol{R b}^{\mathbf{1 , 2 1 1}}$ & $\boldsymbol{N}^{\mathbf{0 , 4 7 4}}$ & $\boldsymbol{R m}^{\mathbf{0 , 5 2 6}}$ & $\boldsymbol{E I}_{\mathbf{3 0}}$ \\
\hline Jan & 8,430 & 14,000 & 2,100 & 13,218 & 0,286 & 1,477 & 34,204 \\
Feb & 4,000 & 8,000 & 2,560 & 5,359 & 0,373 & 1,640 & 20,065 \\
Mar & 11,720 & 6,000 & 8,700 & 19,700 & 0,428 & 3,120 & 160,877 \\
Apr & 12,450 & 9,000 & 3,950 & 21,196 & 0,353 & 2,060 & 94,282 \\
Mei & 11,650 & 6,000 & 3,300 & 19,558 & 0,428 & 1,874 & 95,917 \\
Jun & 7,090 & 17,000 & 1,750 & 10,718 & 0,261 & 1,342 & 22,984 \\
Jul & 0,150 & 2,000 & 0,100 & 0,101 & 0,720 & 0,298 & 0,132 \\
Agst & 0,000 & 0,000 & 0,000 & 0,000 & 0,000 & 0,000 & 0,000 \\
Sept & 1,200 & 4,000 & 0,500 & 1,247 & 0,518 & 0,694 & 2,747 \\
Okt & 1,420 & 2,000 & 1,320 & 1,529 & 0,720 & 1,157 & 7,795 \\
Nov & 5,830 & 7,000 & 2,550 & 8,457 & 0,398 & 1,636 & 33,664 \\
Des & 3,400 & 4,000 & 1,800 & 4,402 & 0,518 & 1,362 & 19,019 \\
\hline \multicolumn{7}{|l|}{ Jumlah } \\
\hline
\end{tabular}


Tabel 5: Perhitungan Faktor Erosivitas Hujan (R) pada Tahun 2003

\begin{tabular}{|l|l|l|l|l|l|l|l|}
\hline Bulan & Rb & $\mathbf{N}$ & $\mathbf{R m}$ & $\boldsymbol{R b}^{\mathbf{1 , 2 1 1}}$ & $\boldsymbol{N}^{\mathbf{- 0 , 4 7 4}}$ & $\boldsymbol{R m}^{\mathbf{0 , 5 2 6}}$ & \multicolumn{1}{|c|}{$\boldsymbol{I}_{\mathbf{3 0}}$} \\
\hline Jan & 5,670 & 10,000 & 1,840 & 8,177 & 0,336 & 1,378 & 23,151 \\
Feb & 22,930 & 7,000 & 9,500 & 44,407 & 0,398 & 3,268 & 353,050 \\
Mar & 4,250 & 9,000 & 2,030 & 5,767 & 0,353 & 1,451 & 18,076 \\
Apr & 2,640 & 10,000 & 0,740 & 3,240 & 0,336 & 0,854 & 5,681 \\
Mei & 6,350 & 11,000 & 2,800 & 9,379 & 0,321 & 1,719 & 31,654 \\
Jun & 0,840 & 3,000 & 0,620 & 0,810 & 0,594 & 0,778 & 2,289 \\
Jul & 3,820 & 9,000 & 1,300 & 5,068 & 0,353 & 1,148 & 12,566 \\
Agst & 2,300 & 10,000 & 0,430 & 2,742 & 0,336 & 0,642 & 3,614 \\
Sept & 2,580 & 4,000 & 1,700 & 3,151 & 0,518 & 1,322 & 13,213 \\
Okt & 6,440 & 10,000 & 2,800 & 9,540 & 0,336 & 1,719 & 33,686 \\
Nov & 4,710 & 7,000 & 1,900 & 6,532 & 0,398 & 1,402 & 22,272 \\
Des & 12,410 & 18,000 & 3,700 & 21,113 & 0,254 & 1,990 & 65,330 \\
\hline \multicolumn{7}{|l|}{ Jumlah } \\
\hline
\end{tabular}

\section{HASIL DAN PEMBAHASAN}

Adapun hal-hal yang digunakan untuk menghitung besarnya erosi potensial sebagai berikut:

\subsection{Faktor Erosivitas Hujan (R)}

Sedangkan rumus untuk menghitung erosivitas hujan adalah :

$E I_{30}=6,12(R b)^{1,211}(N)^{-0,474}(R m)^{0,536}$

Misalnya perhitungan faktor erosivitas hujan (R) bulan januari pada tahun 1999, dimana untuk data curah hujan rata-rata $(\mathrm{Rb})$, jumlah hari hujan rata-rata perbulan $(\mathrm{N})$ dan curah hujan maksimum rata-rata $(\mathrm{Rm})$ diperoleh dari Stasiun Meteorologi dan Geofisika Mutiara Palu.

* Curah hujan rata - rata bulanan $(\mathrm{Rb})=55,0 \mathrm{~mm}=5,50 \mathrm{~cm}$

* Jumlah hari hujan rata-rata perbulan $(\mathrm{N})=11$ hari

- Curah hujan maksimum rata-rata $08,0 \mathrm{~mm}(\mathrm{Rm})=0,8 \mathrm{~cm}$

$E I_{30}=6,12(5,500)^{1,211}(11)^{-0,474}(0,800)^{0,536}=13,76$

\subsection{Faktor Erodibilitas Tanah (K)}

Besarnya nilai $\mathrm{K}$ ditentukan oleh tekstur, struktur, permeabilitas dan bahan organik tanah. Karena nilai $\mathrm{K}$ untuk daerah penelitian belum tersedia, maka disarankan untuk menggunakan nilai $\mathrm{K}$ hasil perkiraan dari nomograf erodibilitas tanah. 
Tabel 6: Daftar Nilai Faktor Erodibilitas (K)

\begin{tabular}{|c|c|c|}
\hline No. & Uraian & Nilai Erodibilitas \\
\hline \multirow{2}{*}{1.} & Kode Sampel $L_{1}-$ I & 0,177 \\
\hline & Kode Sampel $L_{1}-$ II & 0,191 \\
\hline \multirow{2}{*}{2.} & Kode Sampel $L_{2}-\mathrm{I}$ & 0,215 \\
\hline & Kode Sampel $L_{2}-$ II & 0,300 \\
\hline \multirow{2}{*}{3.} & Kode Sampel $L_{3}-$ I & 0,100 \\
\hline & Kode Sampel $L_{3}-$ II & 0,054 \\
\hline \multirow{2}{*}{4.} & Kode Sampel $L_{4}-\mathrm{I}$ & 0,182 \\
\hline & Kode Sampel $L_{4}-$ II & 0,164 \\
\hline \multirow{2}{*}{5.} & Kode Sampel $L_{5}-\mathrm{I}$ & 0,159 \\
\hline & Kode Sampel $L_{5}-$ II & 0,223 \\
\hline \multirow{2}{*}{6.} & Kode Sampel $L_{6}-\mathrm{I}$ & 0,109 \\
\hline & Kode Sampel $L_{6}-$ II & 0,136 \\
\hline \multirow{2}{*}{7.} & Kode Sampel $L_{7}-\mathrm{I}$ & 0,191 \\
\hline & Kode Sampel $L_{7}-$ II & 0,154 \\
\hline \multirow{2}{*}{8.} & Kode Sampel $L_{8}-\mathrm{I}$ & 0,295 \\
\hline & Kode Sampel $L_{8}-$ II & 0,210 \\
\hline
\end{tabular}

\subsection{Faktor Kelerengan (LS)}

Perhitungan nilai faktor LS untuk DAS Lolitasiburi adalah sebagai berikut:

\subsubsection{Sub DAS Lolilotto}

Panjang sungai $(L)=3720 \mathrm{~m}=3,720 \mathrm{Km}$

Luas sub DAS $(A)=398 \mathrm{Ha}=3,980 \mathrm{Km}^{2}$

$\mathrm{d}=\frac{L}{A}=\frac{3,720}{3,980}=0,935 \mathrm{Km}$

Untuk kemiringan lereng $15 \%$

$$
\begin{aligned}
\text { D } & =1,35(\mathrm{~d})+0,26(\mathrm{~S})+2,80 \\
& =1,35(0,935)+0,26(15)+2,80 \\
& =1,262+3,90+2,80=7,962 \mathrm{Km} \\
L_{o} & =\frac{1}{2 D}=\frac{1}{2.7,962}=0,063 \mathrm{Km}=63 \mathrm{~m} .
\end{aligned}
$$

Faktor LS

$$
\begin{aligned}
\text { LS } & =\frac{\sqrt{L_{0}}}{100}\left(1,38+(0,965 . S)+\left(0,138 . S^{2}\right)\right) \\
& =\frac{\sqrt{63}}{100}\left(1,38+(0,965.15)+\left(0,138.15^{2}\right)\right) \\
& =\frac{\sqrt{63}}{100}(46,905)=3,723 \ldots \ldots \ldots \ldots \ldots \ldots \ldots \ldots \ldots \ldots \ldots \ldots \ldots \ldots \ldots \ldots
\end{aligned}
$$


3.3.2. Sub DAS Salumpangu

Panjang Sungai $(L)=3690 \mathrm{~m}=3,690 \mathrm{Km}$

Luas Sub DAS $(A)=288 \mathrm{Ha}=2,880 \mathrm{Km}^{2}$

$\mathrm{d}=\frac{L}{A}=\frac{3,690}{2,880}=1,281$

Untuk Kemiringan Lereng $0 \%$

$$
\begin{aligned}
& \mathrm{D}=1,35(\mathrm{~d})+0,26(\mathrm{~S})+2,80 \\
& =1,35(1,281)+0,26(0)+2,80 \\
& =1,729+0+2,80=4,529 \mathrm{Km} \\
& L_{o} \quad=\frac{1}{2 D}=\frac{1}{2.4,529}=0,110 \mathrm{Km}=110 \mathrm{~m} \\
& \text { LS }=\frac{\sqrt{L_{o}}}{100}\left(1,38+(0,965 . S)+\left(0,138 . S^{2}\right)\right) \\
& =\frac{\sqrt{110}}{100}\left(1,38+(0,965.0)+\left(0,138.0^{2}\right)\right) \\
& =\frac{\sqrt{110}}{100}(1,380)=0,145
\end{aligned}
$$

\subsubsection{Sub DAS Salunipa}

Panjang sungai $(L)=3600 \mathrm{~m}=3,600 \mathrm{Km}$

Luas Sub DAS $(A)=249 \mathrm{Ha}=2,490 \mathrm{Km}^{2}$

$\mathrm{d}=\frac{L}{A}=\frac{3,600}{2,490}=1,446$

Untuk kemiringan lereng $15 \%$

$$
\begin{aligned}
\mathrm{D} & =1,35(\mathrm{~d})+0,26(\mathrm{~S})+2,80 \\
& =1,35(1,446)+0,26(15)+2,80 \\
& =1,952+3,90+2,80=8,652 \mathrm{Km} \\
L_{o} & =\frac{1}{2 D}=\frac{1}{2.8,652}=0,058 \mathrm{Km}=58 \mathrm{Km}
\end{aligned}
$$

Faktor LS

$$
\begin{aligned}
\text { LS } & =\frac{\sqrt{L_{o}}}{100}\left(1,38+(0,965 . S)+\left(0,138 \cdot S^{2}\right)\right) \\
& =\frac{\sqrt{58}}{100}\left(1.38+(0,965.15)+\left(0,138 \cdot 15^{2}\right)\right) \\
& =\frac{\sqrt{58}}{100}(46,905)=3,752 \ldots \ldots \ldots \ldots \ldots \ldots \ldots \ldots \ldots \ldots \ldots \ldots \ldots \ldots \ldots \ldots \ldots
\end{aligned}
$$


Tabel 7: Daftar Nilai Faktor Kemiringan Lereng (LS)

\begin{tabular}{|c|c|c|c|c|}
\hline No. & Nama Sub DAS & $\begin{array}{l}\text { Kelas } \\
\text { Lereng }\end{array}$ & Kemiringan Lereng (S) & Nilai Faktor LS \\
\hline \multirow{3}{*}{1.} & \multirow{3}{*}{ Sub DAS Lolilotto } & III & $15 \leq S<25$ & $\frac{1}{2}(3,723+6,573)=5,148$ \\
\hline & & IV & $25 \leq S<45$ & $\frac{1}{2}(6,573+11,885)=9,229$ \\
\hline & & V & $45 \leq S<75$ dan $S \geq 75$ & $\frac{1}{2}(11,885+18,873)=15,379$ \\
\hline \multirow{4}{*}{2.} & \multirow{4}{*}{$\begin{array}{c}\text { Sub DAS } \\
\text { Salumpanngu }\end{array}$} & I & $0 \leq S \leq 8$ & $\frac{1}{2}(0,145+1,563)=0,854$ \\
\hline & & II & $15 \leq S<25$ & $\frac{1}{2}(3,605+6,404)=5,004$ \\
\hline & & IV & $25 \leq S<45$ & $\frac{1}{2}(6,404+11,661)=9,032$ \\
\hline & & V & $45 \leq S<75$ dan $S \geq 75$ & $\frac{1}{2}(11,661+18,873)=15,267$ \\
\hline \multirow{3}{*}{3.} & \multirow{3}{*}{ Sub DAS Salunipa } & III & $15 \leq S<25$ & $\frac{1}{2}(3,572+6,318)=4,945$ \\
\hline & & IV & $25 \leq S<45$ & $\frac{1}{2}(6,318+11,434)=8,876$ \\
\hline & & $\mathrm{V}$ & $45 \leq \mathrm{S}<75$ dan $\mathrm{S} \geq 75$ & $\frac{1}{2}(11,434+18,873)=15,154$ \\
\hline
\end{tabular}

\subsection{Besarnya Erosi Potensial}

$$
E p=R \times K \times L S
$$

Tabel 8: Pengelompokkan klasifikasi Erosi Potensial DAS Loli Tasiburi pada Tahun 1999

\begin{tabular}{|c|c|c|c|}
\hline $\begin{array}{c}\text { Klasifikasi } \\
\text { Erosi }\end{array}$ & $\begin{array}{c}\text { Luas } \\
(\mathrm{Ha})\end{array}$ & $\begin{array}{c}\text { Persentase } \\
(\%)\end{array}$ & $\begin{array}{c}\text { Besar Erosi } \\
\text { (Ton per Tahun) }\end{array}$ \\
\hline SK & 733,430 & 56,975 & 363198,547 \\
\hline K & 198,090 & 41,599 & 265177,377 \\
\hline S & 4,520 & 1,426 & 9090,913 \\
\hline B & - & - & - \\
\hline SB & - & - & 637466,836 \\
\hline Jumlah & 936,040 & 100,000 & - \\
\hline
\end{tabular}

Tabel 9: Pengelompokkan klasifikasi Erosi Potensial DAS Loli Tasiburi pada Tahun 2000

\begin{tabular}{|c|c|c|c|}
\hline $\begin{array}{c}\text { Klasifikasi } \\
\text { Erosi }\end{array}$ & $\begin{array}{c}\text { Luas } \\
(\mathrm{Ha})\end{array}$ & $\begin{array}{c}\text { Persentase } \\
(\%)\end{array}$ & $\begin{array}{c}\text { Besar Erosi } \\
\text { (Ton per Tahun) }\end{array}$ \\
\hline SK & 494,520 & 29,749 & 331507,457 \\
\hline K & 269,740 & 31,877 & 355210,645 \\
\hline S & 171,780 & 38,374 & 427611,688 \\
\hline B & - & - & - \\
\hline SB & - & - & 1114329,790 \\
\hline Jumlah & 936,040 & 100,000 & \\
\hline
\end{tabular}


Tabel 10: Pengelompokkan klasifikasi Erosi Potensial DAS Loli Tasiburi pada Tahun 2001

\begin{tabular}{|c|c|c|c|}
\hline $\begin{array}{c}\text { Klasifikasi } \\
\text { Erosi }\end{array}$ & $\begin{array}{c}\text { Luas } \\
(\mathrm{Ha})\end{array}$ & $\begin{array}{c}\text { Persentase } \\
(\%)\end{array}$ & $\begin{array}{c}\text { Besar Erosi } \\
\text { (Ton per Tahun) }\end{array}$ \\
\hline SK & 655,110 & 45,968 & 390090,923 \\
\hline K & 250,530 & 44,631 & 378740,588 \\
\hline S & 30,400 & 9,401 & 79777,135 \\
\hline B & - & - & - \\
\hline SB & - & - & - \\
\hline Jumlah & 936,040 & 100,000 & 848608,645 \\
\hline
\end{tabular}

Tabel 11: Pengelompokkan klasifikasi Erosi Potensial DAS Loli Tasiburi pada Tahun 2002

\begin{tabular}{|c|c|c|c|}
\hline $\begin{array}{c}\text { Klasifikasi } \\
\text { Erosi }\end{array}$ & $\begin{array}{c}\text { Luas } \\
(\mathrm{Ha})\end{array}$ & $\begin{array}{c}\text { Persentase } \\
(\%)\end{array}$ & $\begin{array}{c}\text { Besar Erosi } \\
\text { (Ton per Tahun) }\end{array}$ \\
\hline SK & 682,490 & 49,321 & 361942,568 \\
\hline K & 224,410 & 41,575 & 305098,734 \\
\hline S & 29,140 & 9,103 & 66803,832 \\
\hline B & - & - & - \\
\hline SB & - & - & - \\
\hline Jumlah & 936,040 & 100,000 & 733845,134 \\
\hline
\end{tabular}

Tabel 12: Pengelompokkan klasifikasi Erosi Potensial DAS Loli Tasiburi pada Tahun 2003

\begin{tabular}{|c|c|c|c|}
\hline $\begin{array}{c}\text { Klasifikasi } \\
\text { Erosi }\end{array}$ & $\begin{array}{c}\text { Luas } \\
(\mathrm{Ha})\end{array}$ & $\begin{array}{c}\text { Persentase } \\
(\%)\end{array}$ & $\begin{array}{c}\text { Besar Erosi } \\
\text { (Ton per Tahun) }\end{array}$ \\
\hline SK & 706,710 & 53,417 & 381272,684 \\
\hline K & 200,190 & 37,479 & 267513,234 \\
\hline S & 29,140 & 9,103 & 64975,565 \\
\hline B & - & - & - \\
\hline SB & - & - & - \\
\hline Jumlah & 936,040 & 100,000 & 713761,483 \\
\hline
\end{tabular}


Tabel 13: Daftar Erosi Potensial DAS Loli Tasiburi selama 5 Tahun

\begin{tabular}{|c|c|c|c|c|}
\hline \multirow[b]{2}{*}{ No. } & \multirow[b]{2}{*}{ Tahun } & \multirow{2}{*}{$\begin{array}{l}\text { Luas Unit Lahan } \\
\qquad(\mathrm{Ha})\end{array}$} & \multicolumn{2}{|c|}{ Total Erosi Potensial (Ep) } \\
\hline & & & $\begin{array}{l}\text { Ton per } \\
\text { Tahun }\end{array}$ & $\begin{array}{c}\text { mm per } \\
\text { Tahun }\end{array}$ \\
\hline 1. & 1999 & 936,040 & 637466,836 & 37,835 \\
\hline 2. & 2000 & 936,040 & 1114329,790 & 66,137 \\
\hline 3. & 2001 & 936,040 & 733845,134 & 43,555 \\
\hline 4. & 2002 & 936,040 & 713761,483 & 42,363 \\
\hline 5. & 2003 & 936,040 & 848608,645 & 50,366 \\
\hline \multicolumn{3}{|c|}{ Ep selama 5 Tahun } & 4048011,888 & 240,256 \\
\hline
\end{tabular}

Tabel 13 dapat disajikan dalam bentuk diagram di bawah ini :

\section{Total Erosi Potensial yang Terjadi Setiap Tahun}

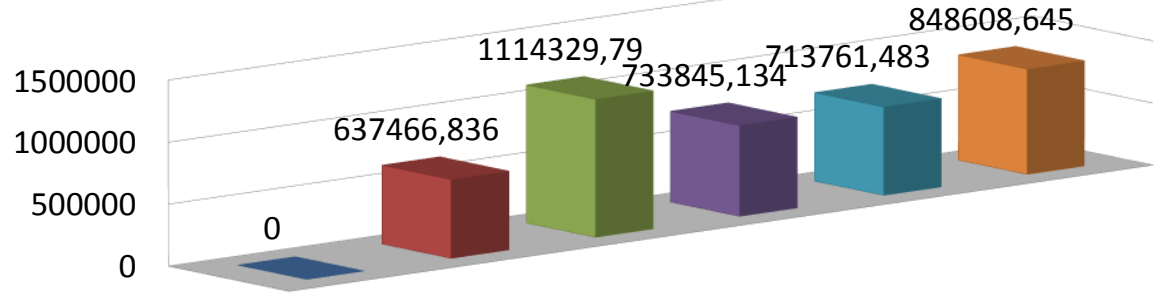

Total Erosi Potensial (Ep)

Tahun $\square 1999 \quad \square 2000 \quad \square 2001 \quad \square 2002 \quad \square 2003$

Gambar 1: Total Erosi Potensial yang Terjadi Setiap Tahun

\section{DAFTAR PUSTAKA}

[1]. Asdak, C. 2002. Hidrologi dan Pengelolaan Daerah Aliran Sungai. Gadjah Mada University Pres. Yogyakarta.

[2]. Sastrodarsono, S dan Tominaga, M. 1984. Perbaikan dan Pengaturan Sungai. Pradya Paramita. Jakarta.

[3]. Suripin. 2002. Pelestarian Sumber Daya Tanah dan Air. Andi. Yogyakarta. 